\title{
Nitrogen, Biochar, and Mycorrhizae: Alteration of the Symbiosis and
} Oxidation of the Char Surface

Chase LeCroy ${ }^{1 *}$, Caroline A. Masiello ${ }^{1 * \star}$, Jennifer A. Rudgers ${ }^{2^{\star \star \star}}$, William C. Hockaday $^{3}$, Jonathan J. Silberg ${ }^{4}$

${ }^{1}$ Department of Earth Science, Rice University ms 126, 6100 Main St., Houston, TX 77030

${ }^{2}$ Department of Ecology and Evolutionary Biology, Rice University, ms 170, 6100 Main St., Houston, TX 77030

${ }^{3}$ Department of Geology, Baylor University, One Bear Place \#97354, Waco, TX 76798

${ }^{4}$ Department of Biochemistry and Cell Biology, Rice University, ms 140, 6100 Main St., Houston, TX 77030

*now at Department of Geography, UCLA, 1255 Bunche Hall, Box 951524, Los Angeles, CA 90095

${ }^{* *}$ corresponding author

${ }^{* * *}$ now at Department of Biology, University of New Mexico, Castetter Hall 286, MSC03 2020, Albuquerque, NM 87131-0001

KEYWORDS: biochar, mycorrhizae, XPS, charcoal, black carbon

HIGHLIGHTS:

-The presence of both fertilizer and biochar in 4 week sorghum pot trials significantly increased root mycorrhizal infection;

-With both fertilizer and biochar, aboveground biomass production was suppressed, suggesting that the plant-fungal relationship had become parasitic; -Increased oxidation of the biochar surface could be detected over the 4-week pot trial using $\mathrm{x}$-ray photoelectron spectroscopy;

-The most biochar oxidation occurred in pots with mycorrhizae but without fertilizer, suggesting mycorrhizal oxidation of biochar. 


\section{Abstract}

In some cases amending soil with biochar improves fertility, although the

35 exact mechanisms through which biochar alters soil processes are not well understood. In other cases, however, biochar amendment can have no effect on

37 plant growth, or can have negative effects. When crop benefits occur, simultaneous amendment with biochar and mineral nutrients causes results that are not additive, suggesting that biochar may be capable of improving the

40 efficiency of nutrient uptake by plants, but the mechanisms of this synergy

41 remain unknown. One possible mechanism that has not been fully explored is

42 alterations to the plant-mycorrhizal fungus mutualism, a relationship that occurs

43 in most land plants. In a 4 week greenhouse experiment, we investigated

44 possible effects of the presence of biochar, mycorrhizal fungi, and nitrogen

45 fertilizer on sorghum seedling growth. Results indicated that the combined

46 treatment of biochar, mycorrhizal fungi, and high nitrogen decreased

47 aboveground plant biomass by $42 \%$ relative to the mycorrhizae and high nitrogen

48 treatment, while simultaneously promoting mycorrhizal root colonization. This is

49 evidence for an induced parasitism of the mycorrhizal fungus in the presence of

50 nitrogen and biochar within the 4 week timescale of our experiments.

51 Using x-ray photoelectron spectroscopy, we found evidence of increased

52 surface oxidation on biochar particles over the 4 weeks of our trial, consistent

53 with sorption of labile, plant derived dissolved organic matter or char oxidation, 54 either via biotic or abiotic processes. Biochar in soils with mycorrhizae but 
55 without sufficient nitrogen showed more surface oxidation than other treatment

56 combinations, and showed a significantly greater fraction of surface carbon

57 present in carbonyl $(-\mathrm{C}=\mathrm{O})$ functionalities. Our results suggest that soil nitrogen

58 acts as a switch controlling the ability of char to influence the mycorrhizal

59 symbiosis and, in turn, the degree to which the fungi oxidize the char surface.

60

61 


\section{Introduction}

Of the emerging renewable energy and biofuel technologies, biomass

pyrolysis (thermal conversion and/or gasification) stands out as a particularly promising option because of its ancillary benefits, not the least of which is a nontraditional approach to carbon capture and sequestration. The thermal decomposition of biomass under the partial exclusion of oxygen is an exothermic reaction that yields heat, water, combustible gases, and organic liquids (bio-oils) (Bridgwater, 2003). About $30 \%$ of the initial biomass carbon can also be retained in the form of charcoal (called biochar if produced intentionally for $\mathrm{C}$ sequestration). The critical step in making biomass pyrolysis sustainable and carbon negative is the incorporation of the biochar into the soil, rather than its combustion for energy. The longevity of biochar carbon in soil is such that net carbon emissions for the process are negative over the timescale of centuries to millennia (Lehmann, 2007). Soil emissions in the form of carbon dioxide, methane, and nitrous oxide could be reduced by a theoretical maximum of $1.8 \mathrm{Pg}$ $\mathrm{CO}_{2}-\mathrm{C}$ equivalent per year, which would create a meaningful sink in comparison to current fossil fuel emissions of 8.7 Pg C per year (Boden et al., 2011; Woolf et al., 2010).

Biochar's effect on plants and mycorrhizal fungi is poorly understood. The literature on this interaction is often contradictory: biochar has been shown to increase and decrease plant growth, $\mathrm{pH}$, mycorrhizal colonization, and nutrient availability (Warnock et al., 2007), or simply have no effect (Habte and Antal, 2010). Biochar has been shown to improve crop productivity in some but not all 
85 circumstances (Bell and Worrall, 2011; Chan et al., 2007, 2008; Rajkovich et al., 86 2012; Schnell et al., 2012; Zhang et al., 2012a; Zhang et al., 2012b). Also

87 confounding is the variety of methods and materials used. For example, the 88 effect of biochar on plant growth can depend on both the feedstock and pyrolysis 89 process (Chan et al., 2008; Rajkovich et al., 2012). Potential mechanisms for 90 generalized biochar improvement in plant growth include a reduction in soil 91 tensile strength (Chan et al., 2007), improved plant access to soil nutrients 92 (Warnock et al., 2007), improved soil water-holding capacity (Atkinson et al., 93 2010; Briggs et al., 2012; Chan et al., 2007; Glaser et al., 2002; Kinney et al., 94 2012; Liu et al., in press; Novak et al., 2012; Revell et al., 2012), and/or changes 95 in the efficiency of plant-fungal interactions (Atkinson et al., 2010; Thies and 96 Rillig, 2009; Warnock et al., 2007). However, the mechanisms underlying effects 97 of biochar on plant growth remain unresolved, making it difficult to predict the 98 conditions under which biochar amendments to soil will promote plant 99 productivity.

100 Other studies have shown that fungi not only respond to the presence of 101 charcoal in soil, but also interact with it, altering it physically and chemically 102 (Hockaday et al., 2006). Long-term environmental alterations of soil charcoal 103 appear to be crucial in the development of an oxidized patina that delivers 104 beneficial ecosystem services, such as high soil cation exchange capacity 105 (Cheng et al., 2006; Cheng et al., 2008). However, the timescale and 106 mechanism of formation of this patina are poorly described. 
Based on previous studies, we hypothesized that soil nitrogen availability

108 would act to alter the plant-fungal relationship. We examined biochar-driven

109 changes in both the plant-fungal relationship and the degree of char surface

110 oxidation and tested whether these interactions vary as a function of nitrogen

111 availability in the soil. We sought to determine if biochar alters plant interactions

112 with mycorrhizal fungi in the presence of high versus low nitrogen fertilizer, and

113 whether it is possible to determine how the relationship was altered by measuring

114 (1) plant size, (2) mycorrhizal colonization, and (3) surface oxidation of the

115 biochar particles. We addressed these questions through a greenhouse pot trial

116 of sorghum plants grown with and without biochar, with and without mycorrhizal

117 infection, and at high and low levels of nitrogen fertilization.

\section{2. Methods}

2.1 General approach to isolating mechanisms of biochar effects

121 Our experimental conditions were designed to focus only on biochar, nitrogen,

122 and the plant-mycorrhizal relationship. Therefore, we selected a highly

123 mycorrhizal plant (sorghum) for a growth trial in soil and hydrologic conditions

124 intended to eliminate other hypothesized benefits of biochar. We selected

125 sorghum because it is highly dependent upon fungal symbionts and because of

126 its importance as an agricultural crop used for food and biofuel (Hata et al.,

127 2010). We chose a soil matrix with a very low tensile strength (sand-enriched) to

128 limit any potential tensile-strength reduction from biochar amendment. We also

129 saturated the pots with water to insure that the presence of biochar did not 
130 introduce a bias by enhancing the soil water content. After four weeks, we

131 quantified the levels of root colonization by arbuscular mycorrhizal fungi grown in

132 conjunction with the sorghum and examined changes in the biochar surface

133 chemistry using $x$-ray photoelectron spectroscopy (XPS).

\subsection{Greenhouse Experimental Design}

We grew sorghum \pm biochar, \pm ammonium nitrate fertilizer, and \pm

137 mycorrhizae in a sandy soil that was watered to saturation. Each treatment was

138 replicated 30 times. We planted seeds in $115 \mathrm{ml}$ Cone-tainer pots (Stuewe \&

139 Sons, model number SC7) filled with a 1:1 ratio of organic potting media (Metro-

140 Mix SB 200, Sun Gro Horticulture Ltd.) and sand (Quikrete, Premium Play Sand)

141 by volume. The Cone-tainers have holes at the bottom, allowing water to drain

142 freely. We inoculated mycorrhizal fungi treatment pots with spores of Glomus

143 intraradices (Reforestation Technologies International), an arbuscular

144 mycorrhizal fungus, by adding $5 \mathrm{~g}$ of inoculum on top of the soil of each pot

145 followed by a cap of sand to prevent contamination by splashing. Nitrogen

146 treatment pots had ammonium nitrate (Aldrich, 99+\% purity) added once per

147 week at the rate of $34 \mathrm{~kg} \mathrm{~N} / \mathrm{ha}$ in the high nitrogen treatment versus $6.7 \mathrm{~kg} \mathrm{~N} / \mathrm{ha}$

148 in the low nitrogen. Biochar treatment pots had $2.6 \%$ biochar by weight added to

149 the growing medium, equivalent to an agricultural amendment rate of 17.6

150 tons $/$ ha applied at a tillage depth of $20 \mathrm{~cm}$. We planted three sorghum seeds in

151 each pot and at the first sign of growth above soil, we thinned the pots to one

152 plant each. All pots were arranged in a fully randomized array in the greenhouse 
153 at $27-35^{\circ} \mathrm{C}$ with no artificial lighting. Watering to saturation occurred every day

154 for four weeks until the plants were harvested.

1552.2 Biochar Production

156 We produced biochar from apple wood (Malus domestica) sawdust (Allied

157 Kenco, Houston, TX, USA). The wood fragments were $5-10 \mathrm{~mm} \times 0.5-1 \mathrm{~mm} \times$

$158 \quad 0.5-1 \mathrm{~mm}$ and the particle size decreased by $25-50 \%$ following pyrolysis. The

159 sawdust was sealed within a 20 liter batch reactor constructed from 306 stainless

160 steel and heated in a propane-fired furnace. Pyrolysis gases were passively

161 vented to a series of heat exchangers at ambient temperature $\left(\sim 30^{\circ} \mathrm{C}\right)$ to

162 remove condensable liquids and bio-oils — preventing their condensation into

163 the biochar. Non-condensable gases were combusted in a secondary (venturi-

164 style) burner used to heat the reactor. The reactor used in this experiment

165 produces approximately $2 \mathrm{~kg}$ biochar per batch, and all of the biochar used in the 166 pot trial was derived from the same batch. The initial heating rate was

167 approximately $5^{\circ} \mathrm{C} /$ minute to a reactor temperature of $\sim 400^{\circ} \mathrm{C}$. Total heating

168 time was approximately 250 minutes. The reactor was allowed to cool to

169 ambient temperature (overnight) before removing the biochar. When removed

170 from the reactor, the biochar was odorless and visually homogenous. Biochar

171 was manually mixed during removal from the reactor vessel to further ensure

172 homogeneity.

$173 \quad 2.3$ Quantifying Sorghum Biomass 
At harvest, we separated the aboveground and belowground portions and dried them in an oven at $45^{\circ} \mathrm{C}$ for several days. Dry weights were taken for both portions.

\subsection{Root Colonization}

We stained the roots of each plant using the ink and vinegar technique (Vierheilig et al., 1998). All stained roots were viewed through a Leica DM2500 microscope at 400x magnification. Thirty fields of view were observed for each sample and the number of views in which hyphae were present was recorded and converted into a percentage (McGonigle et al., 1990).

\subsection{Changes in Surface Chemistry}

We took advantage of the 4 week exposure period in our experiments to determine how the surface chemistry of char was altered by the rhizosphere environment. XPS was used because this method analyzes only the top $10 \mathrm{~nm}$ of the surface of particles. Initial reactions between biochar and its soil environment start at the surface, and XPS allows the sensitive detection of the onset of these reactions. We bulked and sieved the growth medium of each treatment to facilitate picking of biochar fragments using tweezers for XPS analysis on individual pieces of biochar. We used XPS to analyze 5 biochar fragments from each treatment as well as from fresh biochar.

We determined the bonding environments of carbon and oxygen atoms on the surface of biochar particles using a PHI Quantera XPS with an AI X-ray source at $1486.6 \mathrm{eV}$ and $40.7 \mathrm{~W}$. The beam diameter was $200.0 \mu \mathrm{m}$ and the pass energy $26 \mathrm{eV}$. High resolution, low intensity scans were performed to focus 
197 on the bonding environments. The C1s electron was targeted between 280 and $198290 \mathrm{eV}$ with 40 scans. The O1s electron was targeted between 528 and $538 \mathrm{eV}$

199 with 30 scans. We analyzed and deconvoluted spectra into their component 200 functional groups using MultiPak data analysis software (MultiPak V7.0.1, 04 Mar

201 16, Ulvac-Phi, Inc., 1994-2004). Images of biochar particles before and after 202 exposure to soil+plants are available in the Supplemental Material (Figure S1 203 and S2).

2042.6 Statistical Analysis

205 We performed factorial ANOVA using SAS statistical software (SAS v. 9.2, 206 SAS Institute, Inc., Cary, NC). ANOVA models included the response variables 207 of biomass, mycorrhizal colonization rate, and bonding environment percentages 208 and the fixed effects of the biochar treatment $(+/-)$, mycorrhizal fungi treatment $209(+/-)$ and nitrogen treatment (high/low) as well as all possible interactions.

210 3. Results and Discussion

211 3.1 Above- and Below-ground Biomass: Evidence for Biochar- and Nitrogen212 Induced Fungal Parasitism

213 In the presence of high nitrogen, biochar appeared to promote parasitism

214 by mycorrhizal fungi in the initial stages of plant growth explored by this

215 experiment. This is suggested by the decline in biomass relative to other high

216 nitrogen treatment combinations (Figures 1, 2, and 3). The increase in

217 productivity due to nitrogen addition was immediately recognizable in the bimodal

218 distribution of biomass (Figures 1 and 2). The treatment of biochar, mycorrhizae, 219 and high nitrogen caused an increase in root colonization (Figure 3) and a 
220 decrease in aboveground plant biomass with an average that was low enough to

221 approach the level of the unfertilized treatments. We attribute the dramatic

222 decrease in plant biomass to an induced parasitism on the part of the

223 mycorrhizae. If the biochar provides an environment where nitrogen is more

224 readily available to the roots directly, the mycorrhizal hyphae receive the benefit

225 of organic substrates from the plant without providing nitrogen in return.

226 Corroborating this hypothesis is the observed stimulation of mycorrhizal

227 colonization $(+B,+M$, high $N$, Figure 3; see next section).

$228 \quad$ For belowground biomass (Figure 2), statistical analysis revealed no

229 significant effect other than the increase due to high nitrogen addition. A marginal

230 reduction in belowground biomass due to the presence of biochar was nearly

231 significant $(p=0.067)$. This relationship could be driven by the same parasitism

232 observed in the aboveground biomass, lending support to the idea that there is

233 some mechanism by which biochar induces mycorrhizal parasitism at high levels

234 of mineral nitrogen.

235 Both increases and decreases in mycorrhizal abundance have been

236 observed in conjunction with biochar amendments, although an increase is more

237 common (Lehmann et al., 2011). One of the mechanisms suggested by

238 Lehmann et al. (2011) was a reduced utility of the symbiosis with high nutrient

239 and water availability, but our study shows the opposite pattern: mycorrhizae

240 flourished with high levels of nitrogen fertilizer and water. In another study, Elmer

241 and Pignatello (Elmer and Pignatello, 2011) observed a linear trend of increasing

242 mycorrhizal colonization with biochar amendment rate in asparagus plants. Their 
243 result reflects the colonization levels we observed in inoculated soils without 244 biochar $(+\mathrm{M}$, low $\mathrm{N})$ and with biochar $(+\mathrm{M}$, high $\mathrm{N})$, but does not explain the

245 inflated colonization that occurred with the addition of both high nitrogen and

246 biochar. Nitrogen additions have been observed to increase rates of colonization

247 by mycorrhizal fungi in other studies, including studies on Glomus intraradices

248 (e.g (Hodge and Fitter, 2010; Smith and Smith, 2011)), and high levels of

249 nutrients commonly cause mycorrhizal fungi to shift from plant mutualists to plant

250 parasites (e.g. (Antunes et al., 2012; Johnson et al., 1997). The novel

251 observation in our study is that biochar accelerated the transition to parasitism in

252 the presence of high nitrogen.

253 3.2 Biochar Stimulates Mycorrhizal Colonization

254 The treatments with biochar and mycorrhizal inoculation had greater root

255 colonization by the fungus, suggesting that the presence of biochar does

256 stimulate mycorrhizal colonization of roots (Figure 3). Figure 4 shows the

257 microscope view of a normal root (a) and a highly colonized root (b). The blue

258 strands of hyphae show good staining and are easily visible against the cleared

259 root. As expected, the treatments with mycorrhizae inoculation had significantly

260 greater colonization. Contamination within the greenhouse (via spore transport)

261 is likely the cause of the treatments without mycorrhizal inoculation showing

262 some colonization; the growing media were sterilized and the pots were either

263 new or thoroughly washed and bleached.

2643.3 Oxidation of the Biochar Surface Measured by XPS 
Few studies have used XPS to analyze the surface chemistry of biochar, and none have previously been able to control for exposure to mycorrhizal fungi. XPS separates surface carbon functional groups into four categories: -COOR, -

$268 \mathrm{C}=\mathrm{O},-\mathrm{COR}$, and a fourth category that includes $-\mathrm{CH}, \mathrm{C}-\mathrm{C}$, and $\mathrm{C}=\mathrm{C}$ functional

269 groups (Figure 5). Previous work has shown an increase in the oxidation of

270 biochar with weathering, but causes of the oxidation have not been clear. Time

271 scales and methods in previous studies also cover a wide range. Yao et al. (Yao

272 et al., 2010) performed artificial weathering experiments on biochar produced

273 from sewage sludge, using a modified Soxhlet reactor to repeatedly wet the

274 biochar with water at $30^{\circ} \mathrm{C}$ and with and without humic acids for 300 hours. They

275 observed an increase in the $-\mathrm{COOH}$ and $-\mathrm{C}=\mathrm{O}$ groups, but it could not be

276 determined whether the oxidation was biotic or abiotic. Cheng et al. (Cheng et

277 al., 2006) and Zimmerman (Zimmerman, 2010) attributed an observed increase

278 in oxidation of biochar to abiotic processes in incubation. Nguyen et al. (Nguyen

279 et al., 2008) recovered biochar ranging in age from 2 to 100 years in soils that

280 had been subjected to slash-and-burn agriculture. Their time series showed a

281 period of rapid oxidation in the form of an increase in the ratio of oxidized to

282 reduced carbon followed by a subsequent constant oxidation level. However, the

283 time period of reaching this static level was poorly constrained due to the 100

284 year range of biochar age. Zimmerman (Zimmerman, 2010) observed a leveling-

285 off of biochar remineralization rates after a one year laboratory incubation, but

286 the oxidative environment was substantially different from that of the char studied

287 by Nguyen et al. (Nguyen et al., 2008). 
We observed the largest effect on biochar surface chemistry simply from its addition to the plant-soil environment. All biochar exposed to soil+plants for four weeks showed more surface carbon oxidation in the form of increased

291 percentages of $-\mathrm{COR},-\mathrm{C}=\mathrm{O}$, and $-\mathrm{COOR}$ groups (Table 1; Fig. 6). It is

292 theoretically possible that the XPS measurements occasionally sampled hyphae

293 fragments on the surface of the biochar rather than the biochar itself, but if this

294 had affected our measurements, it would have been seen in larger standard 295 deviation for the + mycorrhizae treatments (Table 1). This is not the case, so we 296 can be confident that the biochar surface was sampled, not the mycorrhizal 297 hyphae. Our results suggest that the first stage of biochar patina development 298 involves sorption of dissolved organic compounds in soil, leading to a 299 generalized increase in surface carbon oxidation.

$300 \quad$ Additionally, one treatment showed small, but statistically significant 301 differences in biochar surface oxidation compared to others. The soils with 302 mycorrhizae but low nitrogen caused more oxidation of the biochar surface than 303 the other treatment combinations, and showed a significantly greater fraction of 304 carbon present as carbonyl groups $(-\mathrm{C}=\mathrm{O}$, Figure 6$)$. This treatment had 305 significantly less mycorrhizal colonization than the combined treatment of 306 biochar, mycorrhizae, and high nitrogen, suggesting that the greater oxidation is 307 not due to the quantity of mycorrhizae, but perhaps to their behavior. Fungi have 308 been shown to degrade aromatic structures (Ascough et al., 2010; Hedges et al., 309 1988; Schreiner et al., 2009; Wengel et al., 2006), and the fungal oxidation of 310 lignin produces both aromatic carbonyl $(-\mathrm{C}=\mathrm{O})$ and aromatic acid $(-\mathrm{COOH})$ 
311 functionalities, with carbonyl groups preferentially enriched in the early stages of

312 decomposition (Goni et al., 1993; Hedges et al., 1988). Our observed increase in

313 carbonyl $(-\mathrm{C}=\mathrm{O})$ and lack of increase in carboxyl carbon $(-\mathrm{COOH})$ detected by

314 XPS is consistent with the early stages of fungal oxidation of aromatic materials.

315 It is possible that our low-nitrogen treatment stimulated the metabolism of

316 mycorrhizal fungi, driving the hyphae to more actively seek nutrients and

317 resulting in more extensive oxidation of biochar via extracellular cometabolism.

318 Likewise, the mycorrhizae could have limited their nutrient-seeking efforts if they

319 were not necessary in the combined biochar, mycorrhizae, and high nitrogen

320 treatment, leading to the observed decreased biochar surface oxidation.

321 One possible explanation for the transformation of mycorrhizal fungi from

322 symbionts to parasites in the +biochar, +mycorrhizae, high $\mathrm{N}$ treatment is biochar

323 sorption of molecules used for cellular signalling, a hypothesis that has been

324 suggested by others (Lehmann et al., 2011; Thies and Rillig, 2009; Warnock et

325 al., 2007). To monitor cell density, fungi release non-polar compounds and use

326 the density-dependent accumulation of these extracellular signalling molecules to

327 coordinate decisions within a population (Albuquerque and Casadevall, 2012;

328 Hogan, 2006), such as spore germination (Macko et al., 1970), the transition

329 between different morphological forms (Oh et al., 2001), and growth rate (Chen

330 et al., 2004). In mycorrhizal fungi, coordinated growth during an infection could

331 represent an evolutionary strategy to maintain the symbiotic relationship with

332 plants and maximize their reproductive fitness in the environment. Unfortunately,

333 the molecular details and fitness consequences of cell-cell signalling are not well 
334 understood for any mycorrhizal fungi, including the fungus examined here,

335 Glomus intraradices. There is evidence that Glomus intraradices is exposed to

336 elevated levels of a signalling molecule, tyrosol, during its infection of plants.

337 Legumes infected with Glomus intraradices accumulated tyrosol within the cell

338 walls of their roots, whereas plants lacking an infection do not accumulate this

339 fungal signalling molecule (Schliemann et al., 2008). Tyrosol is a phenolic

340 compound (4-(2-hydroxyethyl)phenol) that has been studied in the human fungal

341 pathogen Candida albicans, in which it regulates growth (Chen et al., 2004).

342 Soils containing biochar may deplete tyrosol and other fungal signalling

343 compounds from plant roots, such as farnesol, farnesoic acid, and

344 dimethoxycinnamate. These fungal signalling compounds are non-polar, like

345 compounds previously shown to adsorb to charcoal and activated carbon

346 (Zackrisson et al., 1996). Biochar interference in the chemical communication

347 between sorghum and mycorrhizal fungi could underlie the transition of

348 mycorrhizal fungi from symbionts to parasites, although more research is needed

349 to document and understand this transformation.

351 4. Conclusion

352 We showed that biochar induced mycorrhizal parasitism in juvenile 353 sorghum plants in the presence of high levels of nitrogen fertilizer. The

354 increased root colonization rates in the treatment with biochar and nitrogen

355 fertilizer along with the much lower aboveground biomass provide supporting

356 evidence for this conclusion. While this parasitism significantly reduced plant 
357 growth in the first 4 weeks, longer studies will be necessary to determine if an 358 effect can be observed in crop yields.

Along with biochar effects on the plant-fungal relationship, we also explored the changes in biochar after exposure to plants, fertilizer, and mycorrhizal fungi. When compared to fresh biochar, we observed changes in the

362 surface chemistry of biochar that had spent four weeks in soil with sorghum. The 363 percentage of carbon in each of the functional groups $-\mathrm{CO},-\mathrm{C}=\mathrm{O}$, and $-\mathrm{COOH}$

364 increased when watered and exposed to the soil environment, regardless of the 365 experimental treatment. We also observed treatment-specific surface chemistry 366 effects. Biochar in the +mycorrhizae, low nitrogen treatment had an increase in 367 the percentage of carbon in the carbonyl fraction versus other soil-exposed 368 biochars. This treatment had significantly less mycorrhizal colonization than the $369+$ mycorrhizae, high nitrogen treatment indicating that this form of oxidation is not 370 correlated with the quantity of mycorrhizae. Given that the only difference

371 between the treatments was the presence of mycorrhizae, biotic oxidation is the

372 likely cause for the increase in the carbonyl fraction. It is possible that the 373 mycorrhizae in the +mycorrhizae, low nitrogen treatment were more active in 374 their search for nutrients due to their nitrogen-limited environment and thus 375 oxidized the biochar further.

377 Acknowledgements

We appreciated the help of Bo Chen with XPS measurements and

379 Prudence Sun and Liz Yin in the greenhouse, and we acknowledge the Rice 
380 Shared Equipment authority, which provided access to the XPS. Rebecca

381 Barnes and Krystle Hodge helped with plant harvesting. Reforestation

382 Technologies generously provided the mycorrhizae used here. We acknowledge

383 support from NSF EAR 0911685, NSF EAR 0949337 and from the Rice

384 University Shell Center for Sustainability.

385

386

387 


\section{References}

Albuquerque, P., Casadevall, A., 2012. Quorum sensing in fungi - a review. Medical Mycology 50, 337-345.

Antunes, P.M., Lehmann, A., Hart, M.M., Baumecker, M., Rillig, M.C., 2012. Longterm effects of soil nutrient deficiency on arbuscular mycorrhizal communities. Functional Ecology 26, 532-540.

Ascough, P.L., Sturrock, C.J., Bird, M.I., 2010. Investigation of growth responses in saprophytic fungi to charred biomass. Isotopes in Environmental and Health Studies 46, 64-77.

Atkinson, C.J., Fitzgerald, J.D., Hipps, N.A., 2010. Potential mechanisms for achieving agricultural benefits from biochar application to temperate soils: a review. Plant Soil 337, 1-18.

Bell, M.J., Worrall, F., 2011. Charcoal addition to soils in NE England: A carbon sink with environmental co-benefits? Science of the Total Environment, The 409, 1704-1714.

Boden, T.A., Marland, G., Andres, R.J., 2011. Global, Regional, and National Fossil-Fuel CO2 Emissions, Carbon Dioxide Information and Analysis Center. Oak Ridge National Laboratory, US Department of Energy, Oak Ridge, TN, USA. Bridgwater, A.V., 2003. Renewable fuels and chemicals by thermal processing of biomass. Chemical Engineering Journal 91, 87-102.

Briggs, C., Breiner, J.M., Graham, R.C., 2012. Physical and Chemical Properties of Pinus ponderosa Charcoal: Implications for Soil Modification. Soil Science 177, 263-268.

Chan, K.Y., Van Zwieten, L., Meszaros, I., Downie, A., Joseph, S., 2007.

Agronomic values of greenwaste biochar as a soil amendment. Australian Journal of Soil Research 45, 629-634.

Chan, K.Y., Van Zwieten, L., Meszaros, I., Downie, A., Joseph, S., 2008. Using poultry litter biochars as soil amendments. Australian Journal of Soil Research 46, 437-444.

Chen, H., Fujita, M., Feng, Q.H., Clardy, J., Fink, G.R., 2004. Tyrosol is a quorum-sensing molecule in Candida albicans. Proceedings Of The National Academy Of Sciences Of The United States Of America 101, 5048-5052. Cheng, C., Lehmann, J., Thies, J., Burton, S., Engelhard, M., 2006. Oxidation of black carbon by biotic and abiotic processes. Organic Geochemistry 37, 14771488.

Cheng, C.H., Lehmann, J., Engelhard, M.H., 2008. Natural oxidation of black carbon in soils: Changes in molecular form and surface charge along a climosequence. Geochimica et Cosmochimica Acta 72, 1598-1610. Elmer, W.H., Pignatello, J.J., 2011. Effect of Biochar Amendments on Mycorrhizal Associations and Fusarium Crown and Root Rot of Asparagus in Replant Soils. Plant Disease 95, 960-966. 
430 Glaser, B., Lehmann, J., Zech, W., 2002. Ameliorating physical and chemical 431 properties of highly weathered soils in the tropics with charcoal -a review.

432 Biology and Fertility of Soils 35, 219-230.

433 Goni, M.A., Nelson, B., Blanchette, R.A., Hedges, J.I., 1993. Fungal degradation

434 of wood lignins - geochemical perspectives from $\mathrm{CuO}$-derived phenolic dimers

435 and monomers. Geochimica et Cosmochimica Acta 57, 3985-4002.

436 Habte, M., Antal, M.J., 2010. Reaction of Mycorrhizal and Nonmycorrhizal

437 Leucaena leucocephala to Charcoal Amendment of Mansand and Soil. Comm Soil

438 Sci Plant An 41, 540-552.

439 Hata, S., Kobae, Y., Banba, M., 2010. Interactions Between Plants and

440 Arbuscular Mycorrhizal Fungi, International Review of Cell and Molecular Biology,

441 Vol 281. Elsevier Academic Press Inc, San Diego, pp. 1-48.

442 Hedges, J., Blanchette, R., Weliky, K., K., Devol, A., 1988. Effects of fungal

443 degradation on the $\mathrm{CuO}$ oxidation products of lignin - a controlled laboratory

444 study. Geochim Cosmochim Ac 52, 2717-2726.

445 Hockaday, W.C., Grannas, A.M., Kim, S., Hatcher, P.G., 2006. Direct molecular

446 evidence for the degradation and mobility of black carbon in soils from ultrahigh-

447 resolution mass spectral analysis of dissolved organic matter from a fire-

448 impacted forest soil. Organic Geochemistry 37, 501-510.

449 Hodge, A., Fitter, A.H., 2010. Substantial nitrogen acquisition by arbuscular

450 mycorrhizal fungi from organic material has implications for $\mathrm{N}$ cycling.

451 Proceedings Of The National Academy Of Sciences Of The United States Of

452 America 107, 13754-13759.

453 Hogan, D.A., 2006. Talking to themselves: Autoregulation and quorum sensing in

454 fungi. Eukaryotic Cell 5, 613-619.

455 Johnson, N.C., Graham, J.H., Smith, F.A., 1997. Functioning of mycorrhizal

456 associations along the mutualism-parasitism continuum. New Phytologist 135,

$457 \quad 575-586$.

458 Kinney, T.J., Masiello, C.A., Dugan, B., Hockaday, W.C., Dean, M.R., Zygourakis,

459 K., Barnes, R.T., 2012. Hydrologic properties of biochars produced at different

460 temperatures. Biomass \& Bioenergy 41, 34-43.

461 Lehmann, J., 2007. Bio-energy in the black. Frontiers in Ecology and the

462 Environment 5, 381-387.

463 Lehmann, J., Rillig, M.C., Thies, J., Masiello, C.A., Hockaday, W.C., Crowley, D., 464 2011. Biochar effects on soil biota - A review. Soil Biology and Biochemistry In

465 Press.

466 Liu, J., Schulz, H., Brandl, S., Miehtke, H., Huwe, B., Glaser, B., in press. Short-

467 term effect of biochar and compost on soil fertility and water status of a Dystric

468 Cambisol in NE Germany under field conditions. Journal of Plant Nutrition and

469 Soil Science.

470 Macko, V., Staples, R.C., Gershon, H., Renwick, J.A.A., 1970. Self-inhibitor of

471 bean rust uredospores - methyl 3,4-dimethoxycinnamate. Science 170, 539-\&. 
McGonigle, T.P., Miller, M.H., Evans, D.G., Fairchild, G.L., Swan, J.A., 1990. A vesicular arbuscular mycorrhizal fungi. New Phytologist 115, 495-501. Nguyen, B.T., Lehmann, J., Kinyangi, J., Smernik, R., Riha, S.J., Engelhard, M.H., 2008. Long-term black carbon dynamics in cultivated soil. Biogeochemistry 89, 295-308.

Novak, J.M., Busscher, W.J., Watts, D.W., Amonette, J.E., Ippolito, J.A., Lima, I.M., Gaskin, J., Das, K.C., Steiner, C., Ahmedna, M., Rehrah, D., Schomberg, H., 2012. Biochars Impact on Soil-Moisture Storage in an Ultisol and Two Aridisols. Soil Science 177, 310-320.

Oh, K.B., Miyazawa, H., Naito, T., Matsuoka, H., 2001. Purification and characterization of an autoregulatory substance capable of regulating the morphological transition in Candida albicans. Proceedings Of The National Academy Of Sciences Of The United States Of America 98, 4664-4668.

Rajkovich, S., Enders, A., Hanley, K., Hyland, C., Zimmerman, A.R., Lehmann, J., 2012. Corn growth and nitrogen nutrition after additions of biochars with varying properties to a temperate soil. Biology and Fertility of Soils 48, 271-284.

Revell, K.T., Maguire, R.O., Agblevor, F.A., 2012. Influence of Poultry Litter Biochar on Soil Properties and Plant Growth. Soil Science 177, 402-408. Schliemann, W., Ammer, C., Strack, D., 2008. Metabolite profiling of mycorrhizal roots of Medicago truncatula. Phytochemistry 69, 112-146.

Schnell, R.W., Vietor, D.M., Provin, T.L., Munster, C.L., Capareda, S., 2012. Capacity of Biochar Application to Maintain Energy Crop Productivity: Soil Chemistry, Sorghum Growth, and Runoff Water Quality Effects. Journal of Environmental Quality 41, 1044-1051.

Schreiner, K.M., Filley, T.R., Blanchette, R.A., Bowen, B.B., Bolskar, R.D., Hockaday, W.C., Masiello, C.A., Raebiger, J.W., 2009. White-Rot BasidiomyceteMediated Decomposition of C 60Fullerol. Environ. Sci. Technol. 43, 3162-3168. Smith, S.E., Smith, F.A., 2011. Roles of Arbuscular Mycorrhizas in Plant Nutrition and Growth: New Paradigms from Cellular to Ecosystem Scales, Annual Review of Plant Biology, Vol 62. Annual Reviews, Palo Alto, pp. 227-250. Thies, J.E., Rillig, M.C., 2009. Characteristics of Biochar: Biological Properties, In: Lehmann, J., Joseph, S. (Eds.), Biochar for Environmental Management. Earthscan, London, pp. 85-102. Vierheilig, H., Coughlan, A.P., Wyss, U., Piche, Y., 1998. Ink and vinegar, a simple staining technique for arbuscular-mycorrhizal fungi. Applied and Environmental Microbiology 64, 5004-5007. Warnock, D.D., Lehmann, J., Kuyper, T.W., Rillig, M.C., 2007. Mycorrhizal responses to biochar in soil - concepts and mechanisms, Plant Soil, pp. 9-20. Wengel, M., Kothe, E., Schmidt, C.M., Heide, K., Gleixner, G., 2006. Degradation of organic matter from black shales and charcoal by the wood-rotting fungus Schizophyllum commune and release of DOC and heavy metals in the aqueous phase. Science of the Total Environment 367, 383-393. 
515 Woolf, D., Amonette, J.E., Street-Perrott, F.A., Lehmann, J., Joseph, S., 2010.

516 Sustainable biochar to mitigate global climate change, Nature Communications,

517 pp. 1-9.

518 Yao, F.X., Arbestain, M.C., Virgel, S., Blanco, F., Arostegui, J., Macia-Agullo, J.A.,

519 Macias, F., 2010. Simulated geochemical weathering of a mineral ash-rich

520 biochar in a modified Soxhlet reactor. Chemosphere 80, 724-732.

521 Zackrisson, O., Nilsson, M., Wardle, D., 1996. Key ecological function of charcoal

522 from wildfire in the Boreal forest. Oikos 77, 10-19.

523 Zhang, A.F., Bian, R.J., Pan, G.X., Cui, L.Q., Hussain, Q., Li, L.Q., Zheng, J.W.,

524 Zheng, J.F., Zhang, X.H., Han, X.J., Yu, X.Y., 2012a. Effects of biochar

525 amendment on soil quality, crop yield and greenhouse gas emission in a Chinese

526 rice paddy: A field study of 2 consecutive rice growing cycles. Field Crops

527 Research 127, 153-160.

528 Zhang, A.F., Liu, Y.M., Pan, G.X., Hussain, Q., Li, L.Q., Zheng, J.W., Zhang, X.H.,

529 2012b. Effect of biochar amendment on maize yield and greenhouse gas

530 emissions from a soil organic carbon poor calcareous loamy soil from Central

531 China Plain. Plant And Soil 351, 263-275.

532 Zimmerman, A.R., 2010. Abiotic and Microbial Oxidation of Laboratory-Produced

533 Black Carbon (Biochar). Environmental Science \& Technology 44, 1295-1301. 


\section{Nitrogen, Biochar, and Mycorrhizae: Alteration of the Symbiosis and Oxidation of the Char Surface}

5 Table Caption

Table 1. Bonding environment percentages averaged for 5 replicates in each group. Data from analysis using MultiPak software.

\begin{tabular}{|c|c|c|c|c|c|c|c|c|}
\hline $\begin{array}{l}\text { Group } \\
\text { Fresh }\end{array}$ & $\begin{array}{l}\text {-COOR } \\
\text { Average }\end{array}$ & $\begin{array}{l}\text { Standard } \\
\text { Deviation }\end{array}$ & $\begin{array}{c}-\mathrm{C}=\mathrm{O} \\
\text { Average }\end{array}$ & $\begin{array}{l}\text { Standard } \\
\text { Deviation }\end{array}$ & $\begin{array}{c}\text {-C-OR } \\
\text { Average }\end{array}$ & $\begin{array}{l}\text { Standard } \\
\text { Deviation }\end{array}$ & $\begin{array}{c}-\mathrm{CH}, \mathrm{C}- \\
\mathrm{C}, \mathrm{C}=\mathrm{C} \\
\text { Average }\end{array}$ & $\begin{array}{l}\text { Standard } \\
\text { Deviation }\end{array}$ \\
\hline Biochar & 1.96 & 1.17 & 3.69 & 1.03 & 13.52 & 0.88 & 80.83 & 2.66 \\
\hline$-\mathrm{M},-\mathrm{N}$ & 3.36 & 1.58 & 7.35 & 3.29 & 22.83 & 4.48 & 66.46 & 8.75 \\
\hline$+\mathrm{M},-\mathrm{N}$ & 4.60 & 0.81 & 9.73 & 1.72 & 24.93 & 4.80 & 60.73 & 6.52 \\
\hline$-\mathrm{M},+\mathrm{N}$ & 3.75 & 0.36 & 6.45 & 0.88 & 22.37 & 1.45 & 67.42 & 2.30 \\
\hline$+\mathrm{M},+\mathrm{N}$ & 1.82 & 3.15 & 9.03 & 2.80 & 21.07 & 2.21 & 66.75 & 4.90 \\
\hline
\end{tabular}


Nitrogen, Biochar, and Mycorrhizae: Alteration of the Symbiosis and

Oxidation of the Char Surface

LeCroy, Masiello, Rudgers, Hockaday, Silberg, in review

\section{Figure Captions}

Figure 1. Average mass of dried aboveground biomass from 30 plants per group. Different letters indicate values that are significantly different as determined by factorial ANOVA. Error bars represent standard error. ([+B]: Biochar added to soil, [+M]: Mycorrhizal innoculum added to soil, [low N]: fertilized with ammonium nitrate at $6.7 \mathrm{~kg} \mathrm{~N} / \mathrm{ha}$, [high N]: fertilized with ammonium nitrate at $34 \mathrm{~kg} \mathrm{~N} / \mathrm{ha}$.)

Figure 2. Average mass of dried belowground biomass from 30 plants per group. Different letters indicate values that are significantly different as determined by factorial ANOVA. Error bars represent standard error.

Figure 3. Root colonization rates for $\sim 25$ plants per treatment. Different letters indicate values that are significantly different as determined by factorial ANOVA. Error bars represent one standard error. The $[+\mathrm{B},+\mathrm{M}$, high $\mathrm{N}]$ treatment significantly increased colonization while decreasing aboveground and total plant biomass relative to other high $\mathrm{N}$ treatments.

Figure 4. Sorghum roots at $400 x$ magnification. 4a) uninfected root. 4b) highly colonized root; the blue ribbons are mycorrhizae growing into and around the root.

Figure 5. XPS spectra of the C1s electron for biochar. Above, fresh biochar; below, biochar grown with fertilizer and mycorrhizal inoculation. The fresh biochar has one dominant peak representing $\mathrm{C}-\mathrm{C}$ bonds. After being in soil, the biochar becomes more oxidized as seen by the extra peaks at higher binding energies.

Figure 6. XPS spectra of Carbon 1s electron, resolved into bonding environment using MultiPak data analysis software. Each group is averaged from five replicate samples that were picked from their respective group of bulked soil. Different letters indicate values that are significantly different as determined by factorial ANOVA. Error bars represent one standard deviation; instrument error is $<5 \%$. Increased oxidation is shown by all the biochars that were added to soil. The treatment with mycorrhizae but low nitrogen fertilizer shows an increase in the percentage of carbon in the carbonyl fraction. 


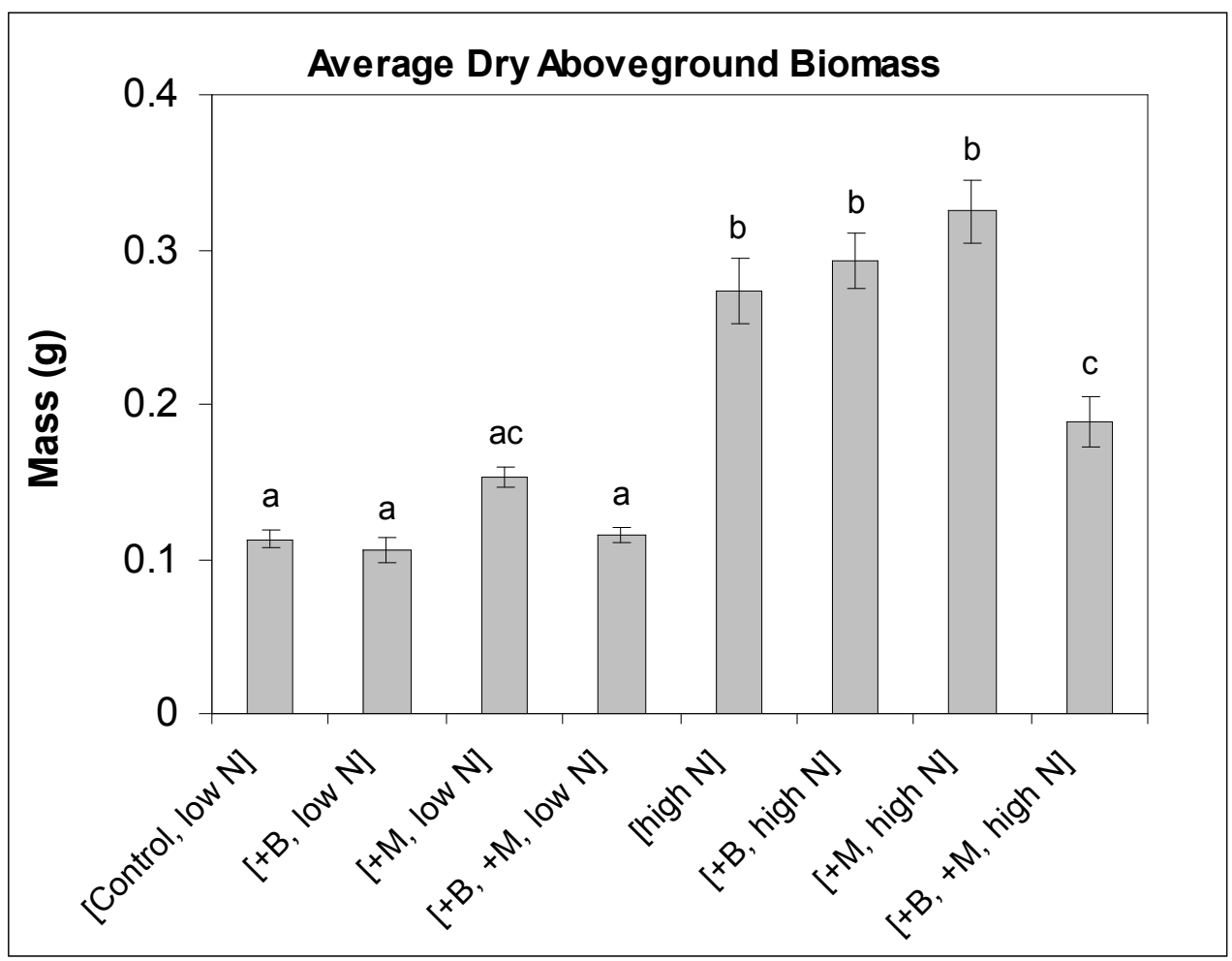

Figure 1. Average mass of dried aboveground biomass from 30 plants per group. Different letters indicate values that are significantly different as determined by factorial ANOVA. Error bars represent one standard error. ([+B]: Biochar added to soil, [+M]: Mycorrhizal innoculum added to soil, [low N]: fertilized with ammonium nitrate at $6.7 \mathrm{~kg} \mathrm{~N} / \mathrm{ha}$, [high N]: fertilized with ammonium nitrate at 34 $\mathrm{kg} \mathrm{N} / \mathrm{ha}$. 


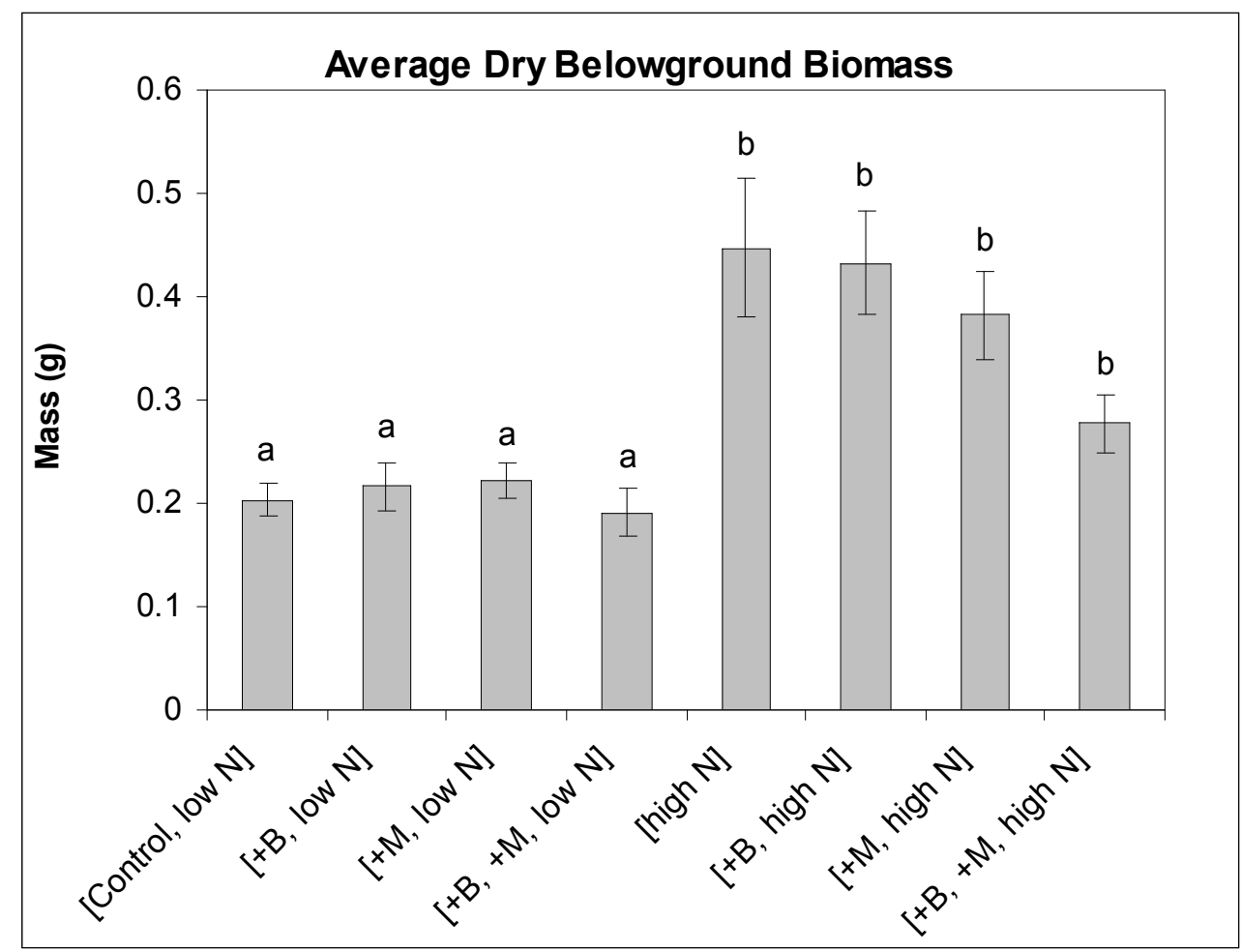

Figure 2. Average mass of dried belowground biomass from 30 plants per group.

Different letters indicate values that are significantly different as determined by factorial ANOVA. Error bars represent standard error. 


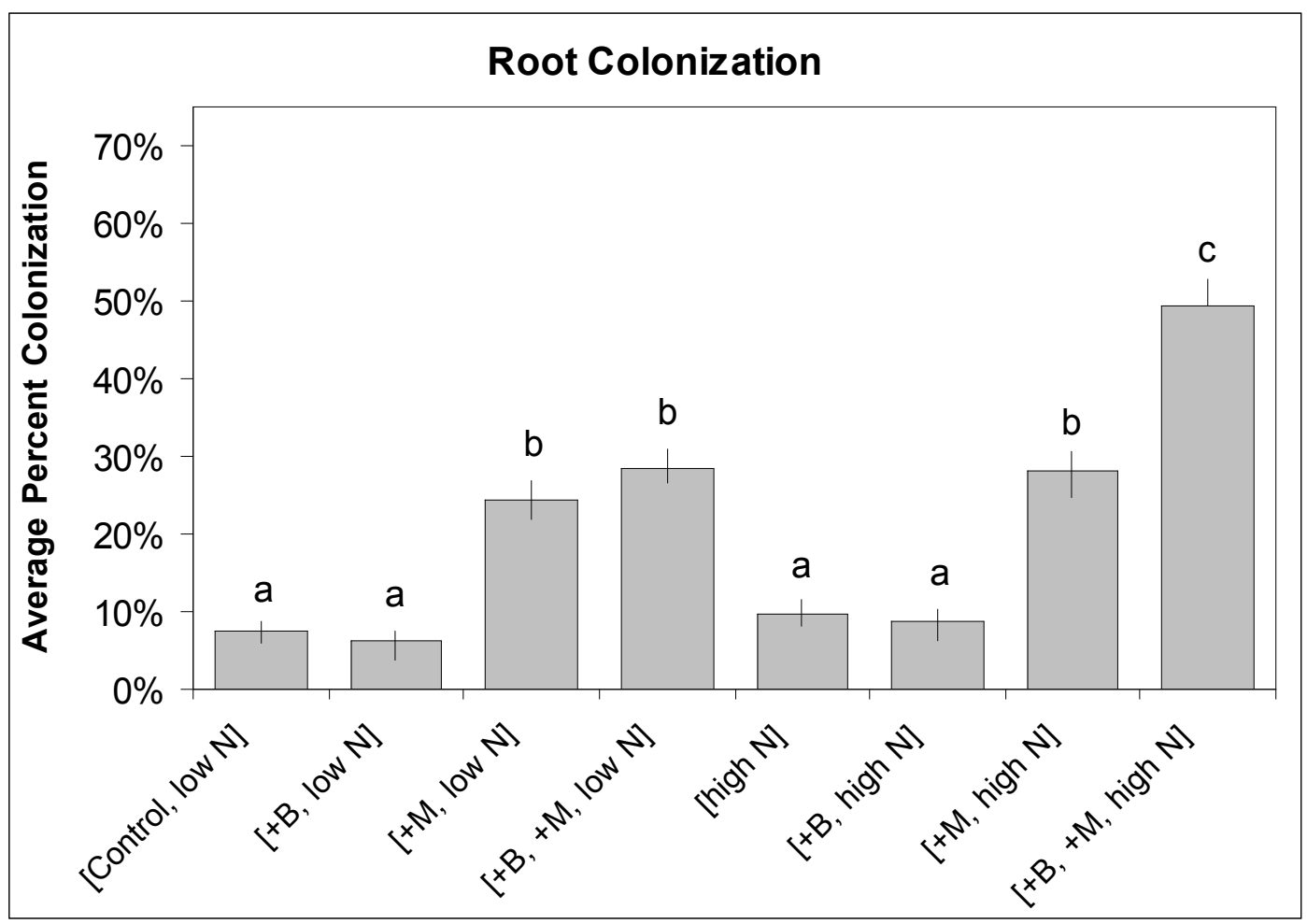

Figure 3. Root colonization rates for $\sim 25$ plants per treatment. Different letters indicate values that are significantly different as determined by factorial ANOVA. Error bars represent one standard error. The $[+\mathrm{B},+\mathrm{M}$, high $\mathrm{N}]$ treatment significantly increased colonization while decreasing aboveground and total plant biomass relative to other high $\mathrm{N}$ treatments. 
a.

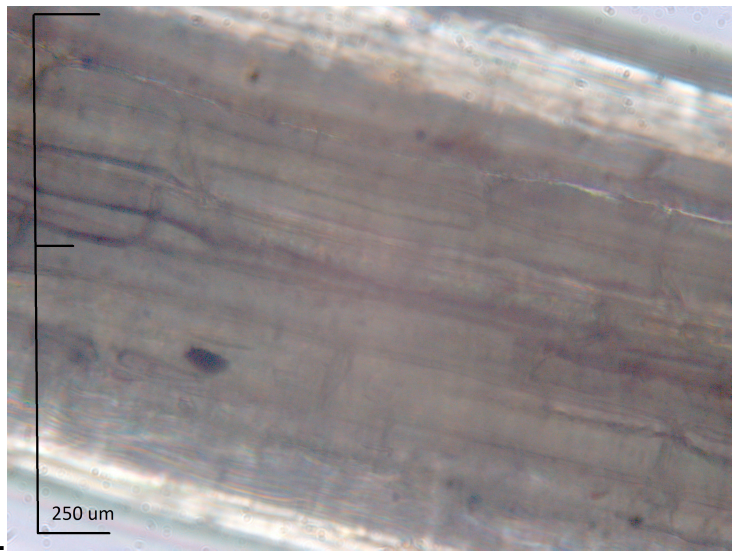

b.

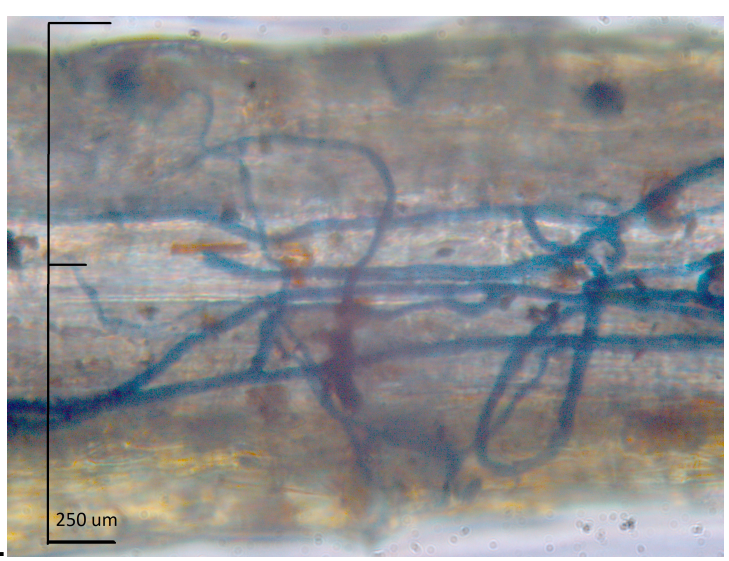

Figure 4. Sorghum roots at 400x magnification. 4a) uninfected root. 4 b) highly colonized root; the blue ribbons are mycorrhizae growing into and around the root. 

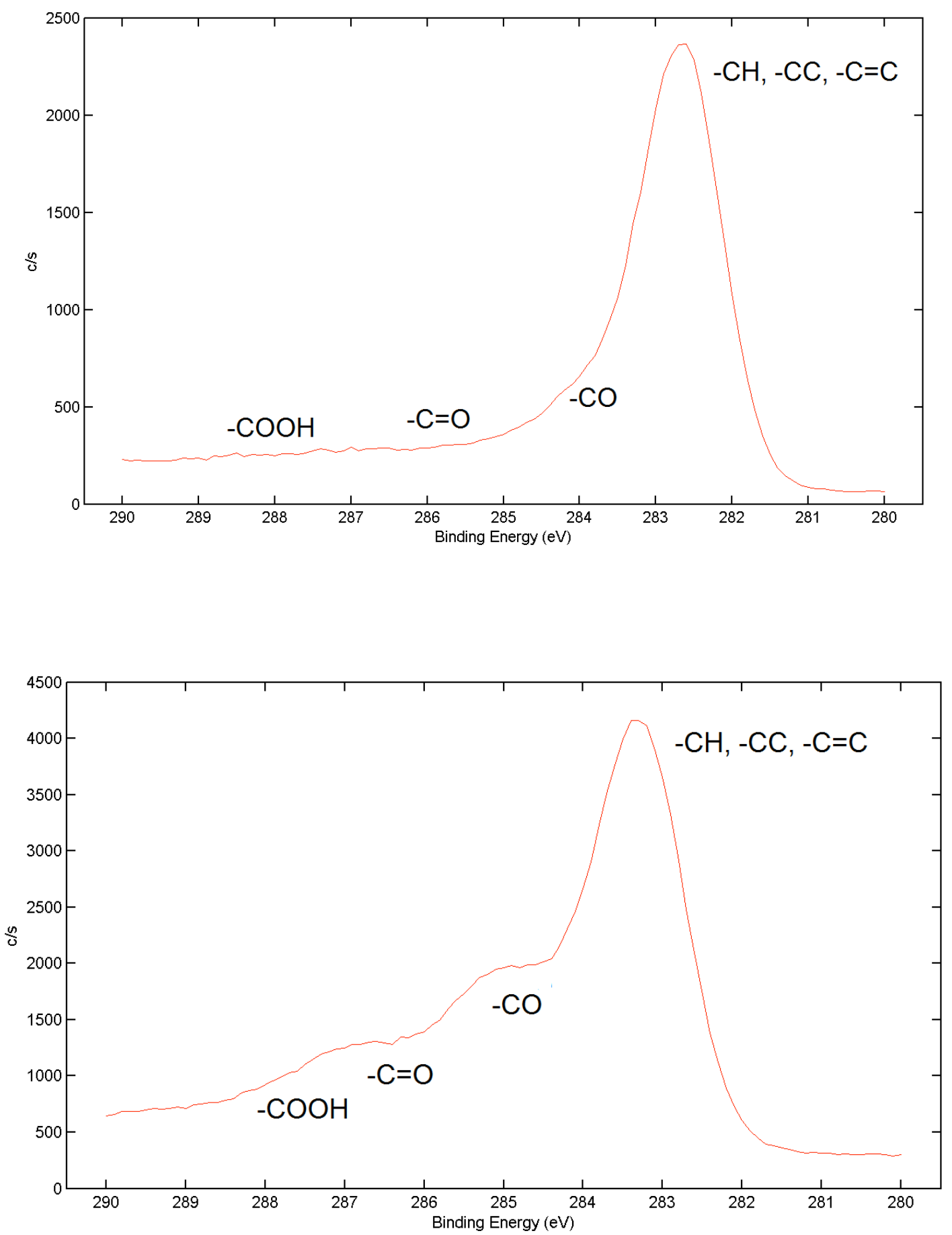

Figure 5. XPS spectra of the C1s electron for biochar. Above, fresh biochar; below, biochar grown with fertilizer and mycorrhizal inoculation. The fresh biochar has one dominant peak representing mostly $\mathrm{C}-\mathrm{C}$ bonds, with the other 
peaks indistinct and overlapping. After being in soil, the biochar becomes more oxidized as seen by the extra peaks at higher binding energies.

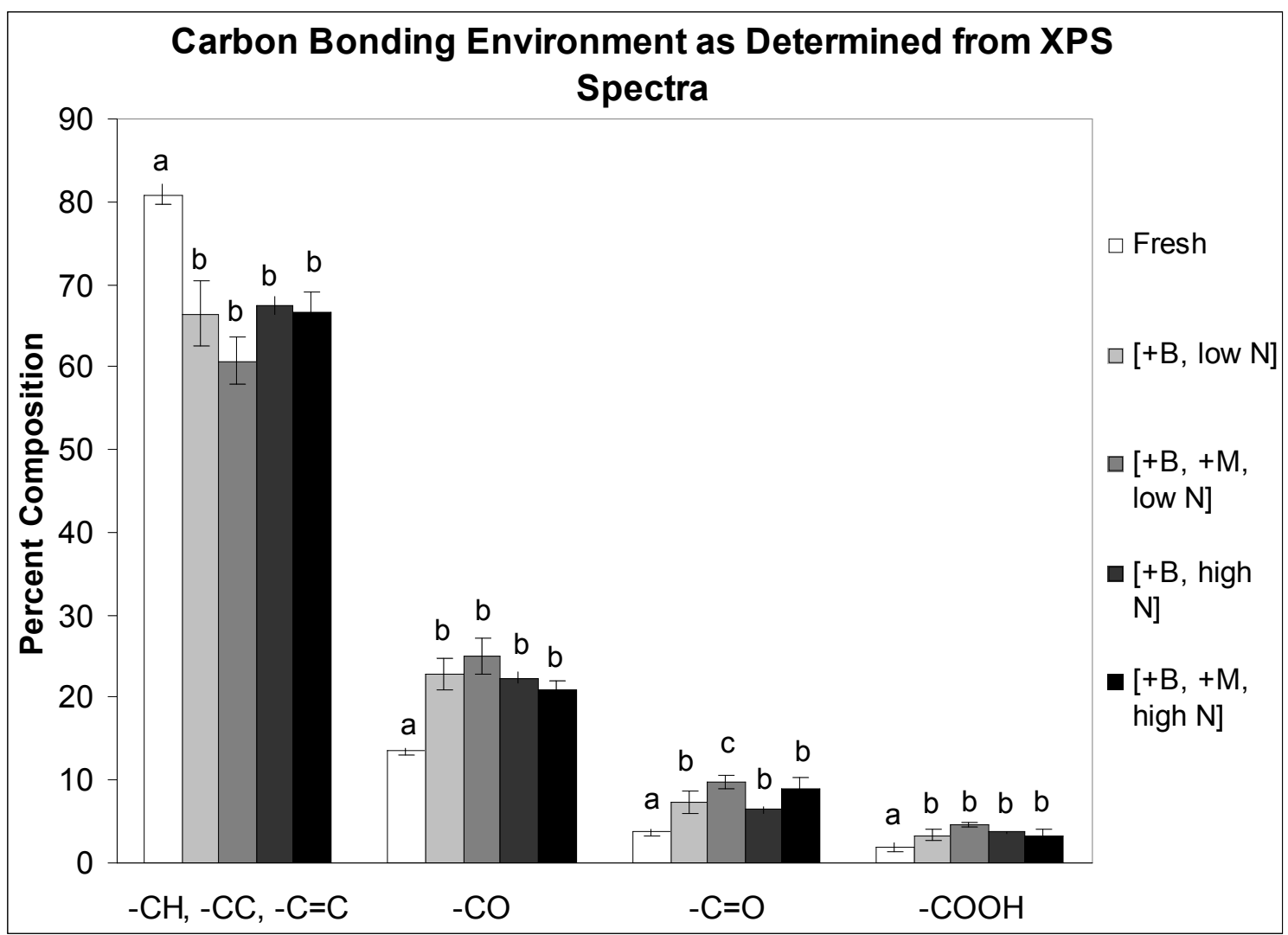

Figure 6. XPS spectra of Carbon 1s electron, resolved into bonding environment using MultiPak data analysis software. Each bar is averaged from five replicate samples that were picked from their respective group of bulked soil. Different letters indicate values that are significantly different as determined by factorial ANOVA. Error bars represent one standard error; instrument error is $<5 \%$. Increased oxidation is shown by all the biochars that were added to soil. The treatment with mycorrhizae but low nitrogen fertilizer shows an increase in the percentage of carbon in the carbonyl fraction. 
Nitrogen, Biochar, and Mycorrhizae: Alteration of the Symbiosis and Oxidation of the Char Surface Chase LeCroy ${ }^{1^{*}}$, Caroline A. Masiello ${ }^{1^{* *}}$, Jennifer A. Rudgers ${ }^{2}$, William C. Hockaday $^{3}$, Jonathan J. Silberg ${ }^{4}$

${ }^{1}$ Department of Earth Science, Rice University ms 126, 6100 Main St., Houston, TX 77030

${ }^{2}$ Department of Ecology and Evolutionary Biology, Rice University, ms 170, 6100 Main St., Houston, TX 77030

${ }^{3}$ Department of Geology, Baylor University, One Bear Place \#97354, Waco, TX 76798

${ }^{4}$ Department of Biochemistry and Cell Biology, Rice University, ms 140, 6100 Main St., Houston, TX 77030

Supplemental Material 
19 Figure S1. Above, an applewood biochar fragment that was in a pot with an

20 inoculated Sorghum plant for 4 weeks. Various particles can be seen on the

21 surface, including soil particles such as vermiculite and perlite along with

22 mycorrhizae. Below, a biochar fragment not exposed to soil.

23

Figure S2. Insets of the biochar fragments from figure S1. The biochar that was in soil, above, has visible minerals and possibly hyphae on its surface while the

26 control biochar, below, has a uniform and plain surface.

27

28

29

30 

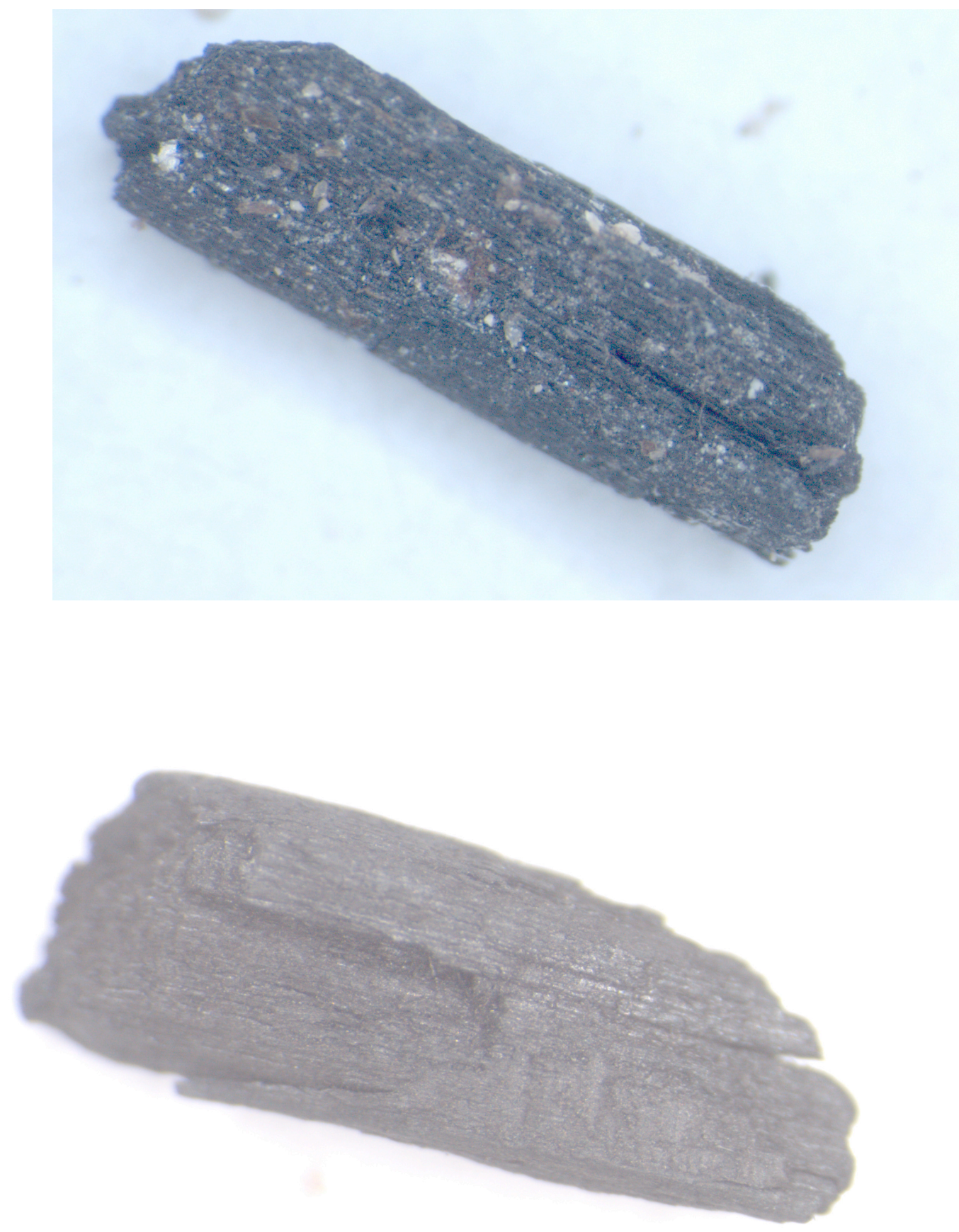

Figure S1. Above, an applewood biochar fragment that was in a pot with 34 an inoculated Sorghum plant for 4 weeks. Magnification is $16 x$. Various particles

35 can be seen on the surface, including soil particles such as vermiculite and 
36 perlite along with mycorrhizae. Below, a biochar fragment that was not present

37 in soil.

38

39

40

41

42

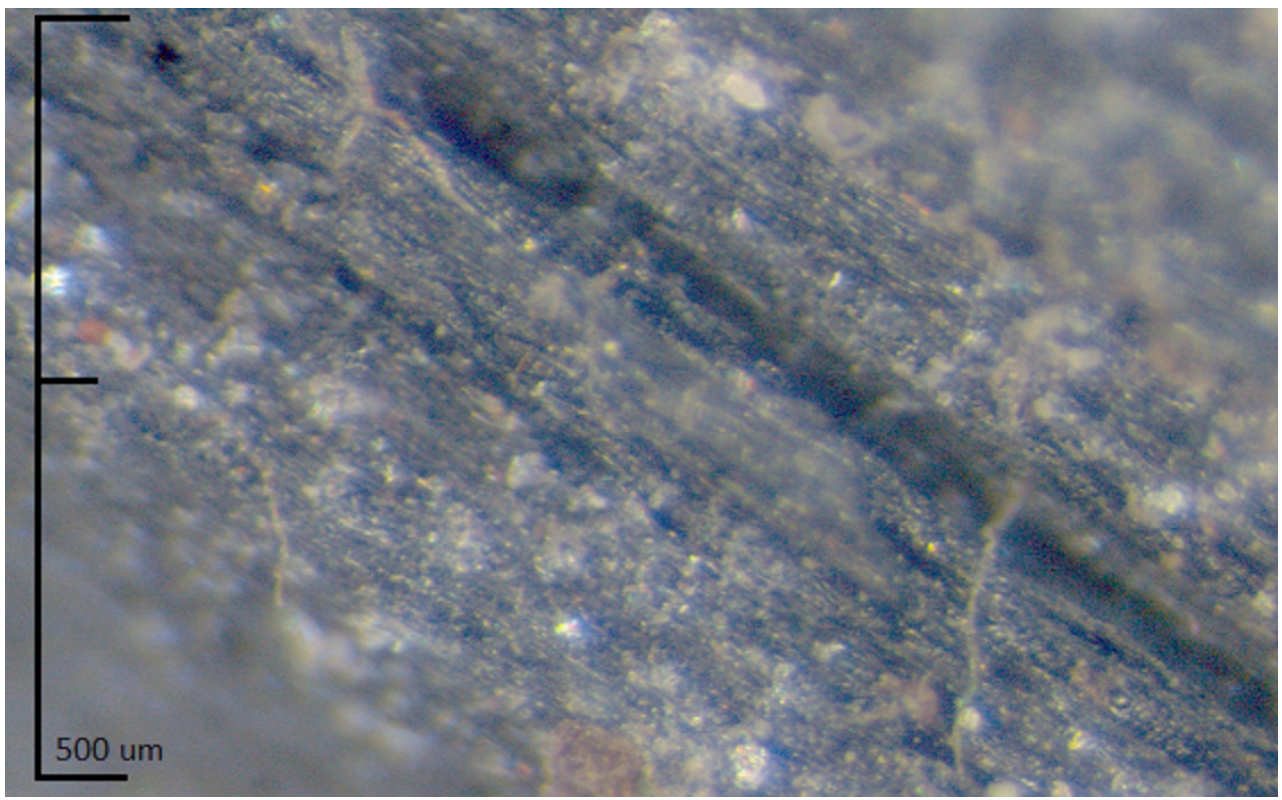

43 


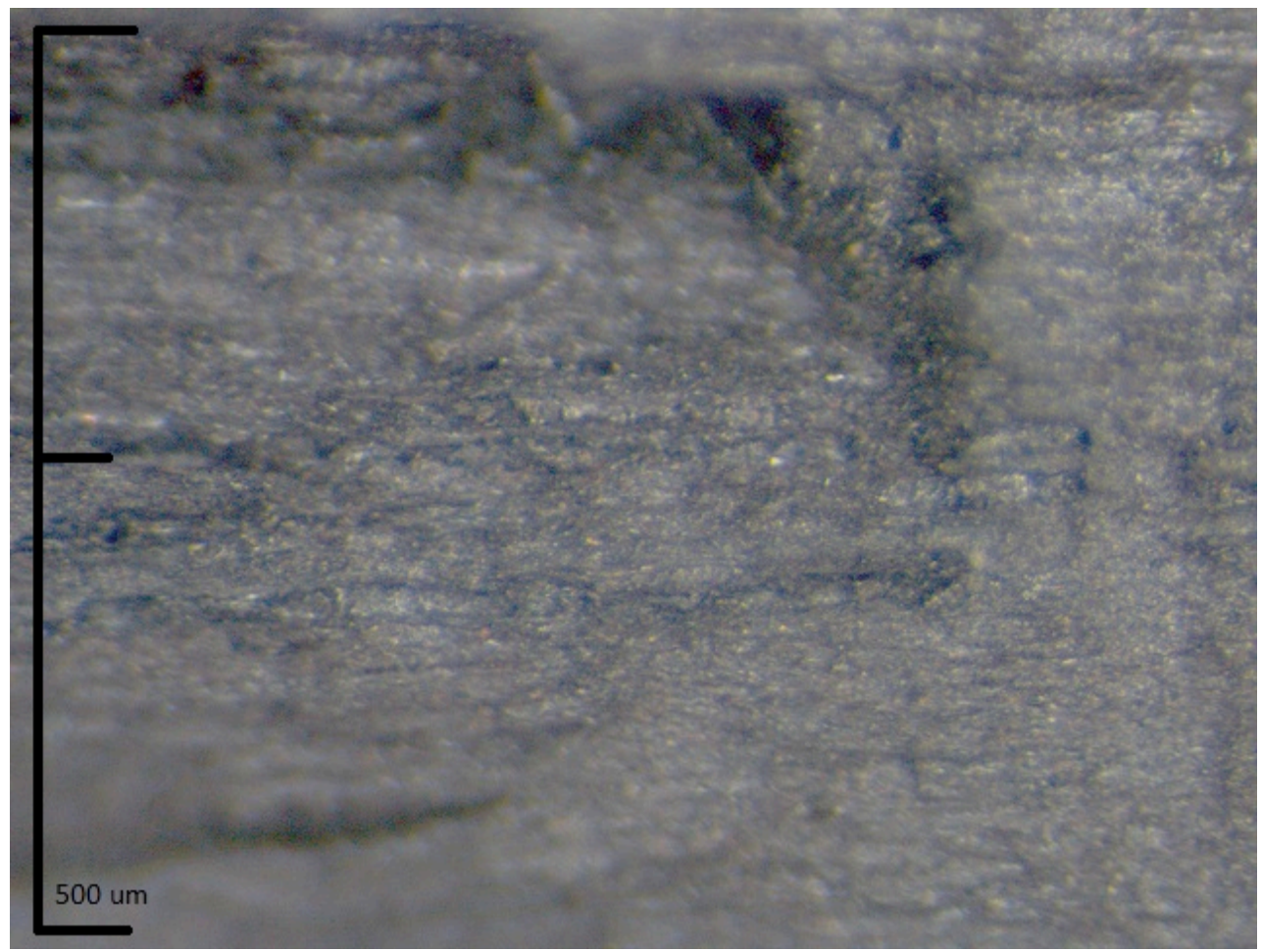

45

Figure S2. Insets of the biochar fragments from figure 5. Magnification is

$47100 x$. The biochar that was in soil, above, has visible minerals and possibly

48 hyphae on its surface while the control biochar, below, has a uniform and plain

49 surface.

50 